Textures and Microstructures, Vol. 30, pp. 191-206 Reprints available directly from the publisher Photocopying permitted by license only
(C) 1998 OPA (Overseas Publishers Association) N.V.

Published by license under the Gordon and Breach Science Publishers imprint. Printed in India.

\title{
AN INVESTIGATION ON GRAIN GROWTH IN A COMMERCIAL Al-Mg ALLOY
}

\author{
I. SAMAJDAR ${ }^{\mathrm{a}, *}$, L. RABET $^{\mathrm{b}}$, B. VERLINDEN ${ }^{\mathrm{a}}$ \\ and P. VAN HOUTTE ${ }^{a}$ \\ a Department MTM, Katholieke Universiteit Leuven, de Croylaan 2, \\ 3001 Heverlee, Belgium; ${ }^{\mathrm{b}}$ Royal Military Academy, Brussels, Belgium
}

(Received 5 August 1997)

\begin{abstract}
Alloy AA5182 contains coarse constituent particles and submicron dispersoids. While the former may cause particle stimulated nucleation (PSN) during primary recrystallization, the fine dispersoids may 'arrest' grain growth during subsequent annealing. Abnormal grain growth was observed after dissolution/coarsening of the dispersoids. Mainly $\mathbf{S}$ $[\{123\}\langle 634\rangle]$ grains, but also some Brass $[\{011\}\langle 112\rangle]$ and $\mathrm{Cu}[\{112\}\langle 111\rangle]$ grains, were observed to grow abnormally. Both the grain size and the grain boundary character distribution (GBCD) possibly played a role in the selection of the grains for abnormal grain growth. A dramatic increase in the number fraction of extremely low angle (1-5 $)$ boundaries was observed with annealing, the increase being more at $470^{\circ} \mathrm{C}$ (when dispersoids were stable and grain growth was arrested more effectively) than at $500^{\circ} \mathrm{C} / 530^{\circ} \mathrm{C}$ (when inhibition to grain growth was less). The nature of the CSL boundaries did not change significantly with annealing time/temperature.
\end{abstract}

Keywords: AA5182; Particle pinning; Grain growth; Grain boundary character distribution; Coincidence site lattice boundary

\section{INTRODUCTION}

Grain boundaries can be characterized by the misorientation, using the usual axis-angle pair (Randle, 1992), and also by the coincidence site lattice (CSL) (Smith and Pond, 1976; Randle, 1992). Relative frequencies of grain boundary types (the so-called grain boundary character distribution (GBCD) (Watanabe, 1992) or Mesotexture (Randle, 1992) may provide crucial information on the structure-property

\footnotetext{
*Corresponding author. Fax: (+32) 16321992.
} 
TABLE I Weight percentages of the major alloying elements in AA5182

\begin{tabular}{lccc}
\hline$S i$ & $F e$ & $M n$ & $M g$ \\
\hline 0.15 & 0.32 & 0.29 & 4.3 \\
\hline
\end{tabular}

relationships and several attempts have been made to understand and to control it - Randle and Brown (1989), Watanabe et al. (1989), Palumbo et al. (1991), Watanabe (1992), Chiba et al. (1994), Hayakawa et al. (1997). Grain growth is often considered to affect the frequencies of different types of grain boundaries (Randle and Brown, 1989; Watanabe et al., 1989; Humphreys and Hatherly, 1995) and may be used as a tool for the GBCD control. The frequencies of low energy boundaries (such as low angle boundaries and low $\Sigma$ boundaries) are expected (Humphreys and Hatherly, 1995), and were experimentally observed (Randle and Brown, 1989; Watanabe et al., 1989), to increase with grain growth. However, our understanding of the effects of annealing and grain growth (especially when it may involve particle coarsening/ dissolution) on the GBCD in commercial alloys is far from complete.

In the present study, an effort will be made to outline change(s) in grain sizes and GBCD of a commercial Al-Mg-Mn alloy of type AA5182 (for details on chemical composition see Table I), as a function of annealing times and for $470^{\circ} \mathrm{C}, 500^{\circ} \mathrm{C}$ and $530^{\circ} \mathrm{C}$ annealing. The microstructure of this alloy is characterized by a large amount of submicron dispersoids with an average size of $0.2 \mu \mathrm{m}$ and a spacing of $1-3 \mu \mathrm{m}$, and by coarse constituent particles with an average size of $5.6 \mu \mathrm{m}$ and an average interparticular spacing of $12 \mu \mathrm{m}$ (Ratchev et al., 1995; Rabet, 1996). While some of the dispersoids, potential causes for grain boundary pinning, may get dissolved at and above $500^{\circ} \mathrm{C}$, the constituent particles are stable for the range of grain growth temperatures used in this study (Ratchev et al., 1995; Rabet, 1996). Abnormal grain growth, initiated by the dissolution/coarsening of the dispersoids, was also studied in terms of global textural changes and possible 'selection' mechanisms (selecting or favoring grains of certain orientations).

\section{EXPERIMENTAL METHODS}

The alloy AA5182 was obtained in as cold-rolled condition (rolling strain of $\varepsilon=1.2$ ) from Hoogovens Aluminium. The submicron 
dispersoids are present as rhombohedral and platelike particles and the former are expected to dissolve at and above $500^{\circ} \mathrm{C}$ (Ratchev et al., 1995). The cold-rolled material was annealed at $470^{\circ} \mathrm{C}, 500^{\circ} \mathrm{C}$ and $530^{\circ} \mathrm{C}$ in a salt bath. Full recrystallization at these temperatures was observed to take only 1-5s (Rabet, 1996; Samajdar et al., 1997). Subsequently after annealing, the macroscopic texture was measured by X-ray diffraction using the software MTM-FHM (Van Houtte, 1995). This software uses the standard series expansion method (Bunge, 1982).

Measurements of microtexture and grain boundary characterizations were obtained by Orientation Imaging Microscopy (OIM) on surfaces containing rolling (RD) and normal (ND) directions, using the standard TSL ${ }^{\mathrm{TM}}$ OIM software. For OIM measurements, at least (and often more) an area of $1000 \mu \mathrm{m}$ by $200 \mu \mathrm{m}$ was used. CSL boundaries were identified using Brandon's criteria (Brandon, 1966), i.e. CSL tolerance being $15^{\circ} / \Sigma^{0.5}$. Grains were identified as regions without $>1^{\circ}$ boundaries inside, as $0-1^{\circ}$ relative misorientations were considered within the tolerance of the OIM measurements. Area and number fractions of such $>1^{\circ}$ misoriented regions were measured by OIM and grain size distributions were calculated by assuming circular grains with $\pi d^{2} / 4$ as area, where $d$ is the equivalent grain diameter (or the grain size). OIM measurements of grain sizes were further confirmed by measurements using the standard linear intercept technique. Constituent particles were identified from the low confidence index of the measurements and were substantiated by backscattered electron imaging in SEM. For grain size and GBCD measurements, points with low confidence index (i.e. unsolvable patterns, or when the beam did strike second phase particles) were filtered out. Both the total number and the number of different types of grain boundaries (as seen in linear scans) were estimated and the grain boundary types were represented as corresponding number fractions. Details of the OIM sample preparation is described elsewhere (Samajdar et al., 1997).

\section{RESULTS}

\section{Changes in Grain Size with Annealing}

Figure 1 plots the grain sizes as a function of the natural logarithm of the annealing time (in s) and for $500^{\circ} \mathrm{C}$ annealing. The material 


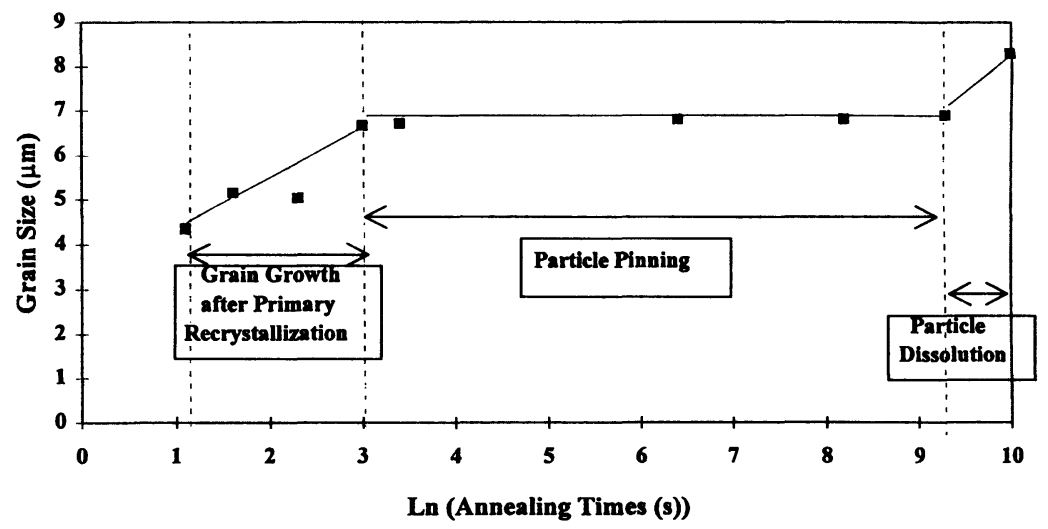

FIGURE 1 Grain size as a function of annealing times (s) (logarithmic scale) for annealing at $500^{\circ} \mathrm{C}$.

recrystallized fully after $3 \mathrm{~s}$ annealing with an average grain size of $4.35 \mu \mathrm{m}$. Further annealing to $20 \mathrm{~s}$ was observed to increase the average grain size to $6.7 \mu \mathrm{m}$. Between 20 and $10800 \mathrm{~s}$, the average grain size did not change much. Further increases in grain sizes were observed only at and above $21600 \mathrm{~s}$. Annealing at $470^{\circ} \mathrm{C}$ or $530^{\circ} \mathrm{C}$ provided similar 'limiting' grain sizes of approximately $7 \mu \mathrm{m}$. At $470^{\circ} \mathrm{C}$, no subsequent grain growth was observed (i.e. after reaching the limiting grain size), while grain growth was observed at and above $10800 \mathrm{~s}$ for $530^{\circ} \mathrm{C}$ annealing. Qualitative observations using backscattered electron imaging on the electropolished samples showed no significant change in particle distribution (especially for the visible fine dispersoids) at $470^{\circ} \mathrm{C}$. With prolonged heating at relatively higher temperatures $\left(10800 \mathrm{~s}\right.$ at $500^{\circ} \mathrm{C}$ and $3600 \mathrm{~s}$ at $530^{\circ} \mathrm{C}$ ), however, interparticle spacings of the fine dispersoids were observed to increase. As the dispersoids are considered (Ratchev et al., 1995; Rabet, 1996) to be mainly responsible for the grain boundary pinning, changes in dispersoid spacings may explain the observed subsequent (i.e. after reaching the limiting grain size) grain growth at $500^{\circ} \mathrm{C} / 530^{\circ} \mathrm{C}$ and no apparent grain growth at $470^{\circ} \mathrm{C}$.

\section{Changes in GBCD with Annealing}

An effort was also made to characterize the possible change(s) in GBCD during annealing. Figure 2(a) plots the number fraction of 
grain boundaries as a function of misorientation angle, for different annealing times at $470^{\circ} \mathrm{C}$. Figure 2(a) starts with annealing time of $30 \mathrm{~s}$, as before $30 \mathrm{~s}$ changes in GBCD were relatively less significant and no distinct trend could be established. Grain boundary misorientations were considered from $1^{\circ}$ to $62.8^{\circ}$, as boundaries between $0^{\circ}$ and $1^{\circ}$ are within the tolerance of the OIM measurements. The frequencies of grain boundaries in random textured material (Samajdar and Doherty, 1994) are also plotted in the figure. As shown in the figure, although the grain size did not change significantly after $30 \mathrm{~s}$, prolonged annealing at $470^{\circ} \mathrm{C}$ increased the fraction of extremely low angle $\left(1-5^{\circ}\right)$ boundaries - an increase from 0.014 to 0.11 , as annealing time increased from 30 to $21600 \mathrm{~s}$. Note that after reaching a relative maxima of approximately 0.11 (as in Fig. 2(a)), the fraction of $1-5^{\circ}$ boundaries did not increase further with subsequent annealing.

The initial misorientation distributions were similar (i.e. after $30 \mathrm{~s}$ annealing at $470^{\circ} \mathrm{C}, 500^{\circ} \mathrm{C}$ and $530^{\circ} \mathrm{C}$ ) and qualitatively similar changes (as in Fig. 2(a)) were observed during annealing at $500^{\circ} \mathrm{C}$ and $530^{\circ} \mathrm{C}$. In other words, the fractions of extremely low angle $1-5^{\circ}$ boundaries were observed to reach an approximate maxima and then roughly stabilize for all three annealing temperatures. Although at $470^{\circ} \mathrm{C}$ grain growth was effectively 'arrested' above $30 \mathrm{~s}$ annealing, grain growth (in the form of noticeable increase in average grain size) was observed at and above 21600 and $10800 \mathrm{~s}$ for $500^{\circ} \mathrm{C}$ and $530^{\circ} \mathrm{C}$ annealing respectively. Interestingly, the initiation of such grain growth did not change the relative maxima of $1-5^{\circ}$ boundaries. Figure $2(\mathrm{~b})$ plots the grain

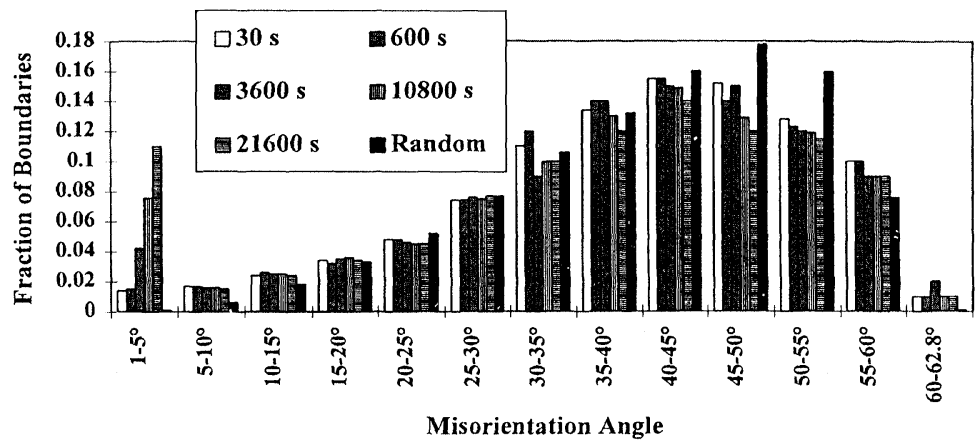

FIGURE 2(a) Fraction of boundaries as a function of misorientation angle for $470^{\circ} \mathrm{C}$ annealed material. 


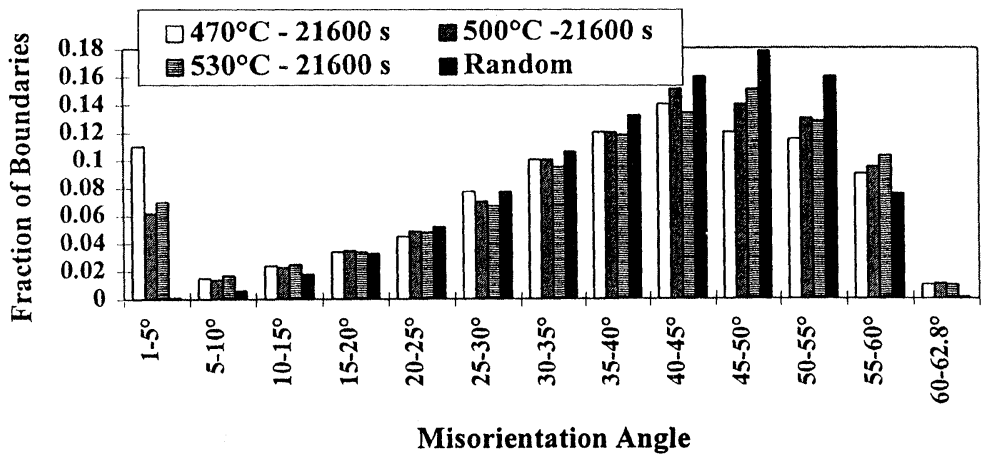

FIGURE 2(b) Fraction of boundaries as a function of misorientation angle after $21600 \mathrm{~s}$ annealing at $470^{\circ} \mathrm{C}, 500^{\circ} \mathrm{C}$ and $530^{\circ} \mathrm{C}$.

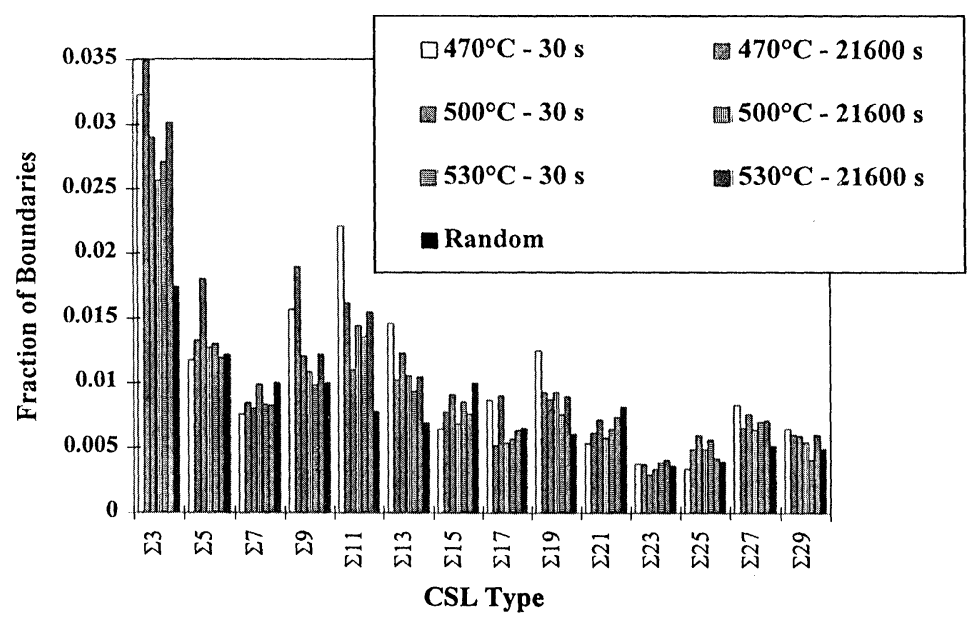

FIGURE 3 Fraction of CSL boundaries after different annealing treatments.

boundary fractions (as function of misorientation angle and using the same conventions as in Fig. 2(a)) after $21600 \mathrm{~s}$ annealing at $470^{\circ} \mathrm{C}$, $500^{\circ} \mathrm{C}$ and $530^{\circ} \mathrm{C}$. Interestingly enough, the fraction of extremely low angle $\left(1-5^{\circ}\right)$ boundaries were larger after annealing at $470^{\circ} \mathrm{C}$ (when the grain growth was largely restricted) than at $500^{\circ} \mathrm{C} / 530^{\circ} \mathrm{C}$ (when limited grain growth was observed).

Figure 3 plots the number fraction of CSL boundaries $(\Sigma 3-\Sigma 29)$ after different annealing treatments. Fraction of CSL boundaries 
expected in a random structure (Watanabe, 1992) are also marked on the figure. As shown in Fig. 3, the nature of the CSL boundaries (both in terms of the total fraction and also for particular CSL types) did not change significantly with annealing time/temperature. Number fraction of grain boundaries (both in terms of misorientation and CSL fraction) were calculated from two OIM scans of $1000 \mu \mathrm{m}$ by $200 \mu \mathrm{m}$ in each sample and average values of such boundary fractions are reported in Figs. 2 and 3.

\section{Abnormal Grain Growth}

\section{III(a). Changes in Bulk Texture}

$\mathrm{X}$-ray texture results were analyzed using orientation distribution functions (ODF) (Bunge, 1982). Volume fractions for different orientations were measured from X-ray ODFs by convoluting with appropriate model functions, where the model functions had a maximum integrated ODF value of 1 and used a Gaussian spread of $16.5^{\circ}$ (Van Houtte, 1995). No significant textural changes (and also no apparent abnormal grain growth) were observed during $470^{\circ} \mathrm{C}$ annealing. During $500^{\circ} \mathrm{C}$ or $530^{\circ} \mathrm{C}$ prolonged annealing, however, a considerable increase in rolling texture components was observed. Figure 4 plots the volume fractions of Goss $[\{011\}\langle 100\rangle]$, Brass $[\{011\}\langle 112\rangle]$,

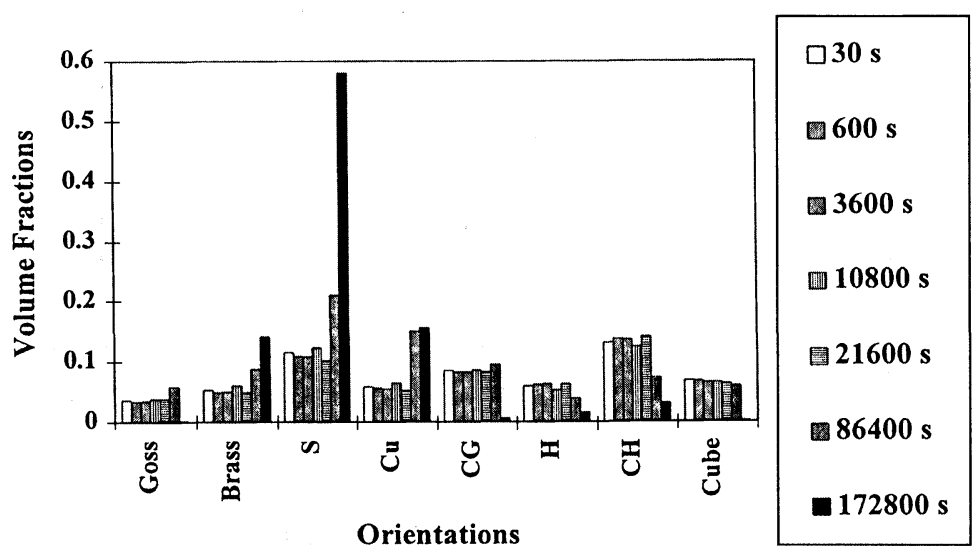

FIGURE 4 Volume fractions of different orientations as a function of annealing times $\left(530^{\circ} \mathrm{C}\right.$ annealing). 
$\mathrm{S}[\{123\}\langle 634\rangle], \mathrm{Cu}[\{112\}\langle 111\rangle]$ and $\mathrm{CG}[\{012\}\langle 110\rangle]$ (all of which belong to the usual fcc rolling texture) and aiso for Cube $[\{001\}\langle 100\rangle]$, $\mathrm{H}[\{001\}\langle 110\rangle]$ and $\mathrm{CH}[\{001\}\langle 120\rangle]$ (the last two belonging to the potential PSN orientations) (Rabet, 1996; Samajdar et al., 1997), as function of annealing times (in s, for $530^{\circ} \mathrm{C}$ annealing). As shown in the figure, till $21600 \mathrm{~s}$ annealing the volume fractions of individual orientations do not change noticeably. Above $21600 \mathrm{~s}$, marked increase in rolling texture orientations (especially for $\mathrm{S}$ ) did coincide with significant abnormal grain growth. Observed textural changes on the X-ray ODFs were further substantiated by OIM scans.

\section{III(b). Selection Mechanisms}

OIM scans revealed abnormal grain growth above 36000 and $21600 \mathrm{~s}$ for $500^{\circ} \mathrm{C}$ and $530^{\circ} \mathrm{C}$ respectively, as mainly $\mathrm{S}$ grains (and also some Brass and $\mathrm{Cu}$ grains) grew massive. In order to understand the selection mechanisms of the abnormal grain growth, both the GBCD (measured with respect to ideal orientations) and grain size distributions (within $20^{\circ}$ of individual orientations) were studied.

Figure 5(a) plots the number fraction of $1-10^{\circ}$ and $10-20^{\circ}$ boundaries which an ideal $\mathrm{S}, \mathrm{Brass}, \mathrm{Cu}, \mathrm{CG}, \mathrm{H}$ and $\mathrm{CH}$ orientation will have with the grains present in the $500^{\circ} \mathrm{C} / 3 \mathrm{~s}$ annealed sample. Number fractions of such boundaries for ideal Goss orientation (which are not given in Fig. 5(a)) were observed to be similar to $\mathrm{S} / \mathrm{Brass} / \mathrm{Cu}$. Grains outside these six orientations, and selected at random from the OIMs,

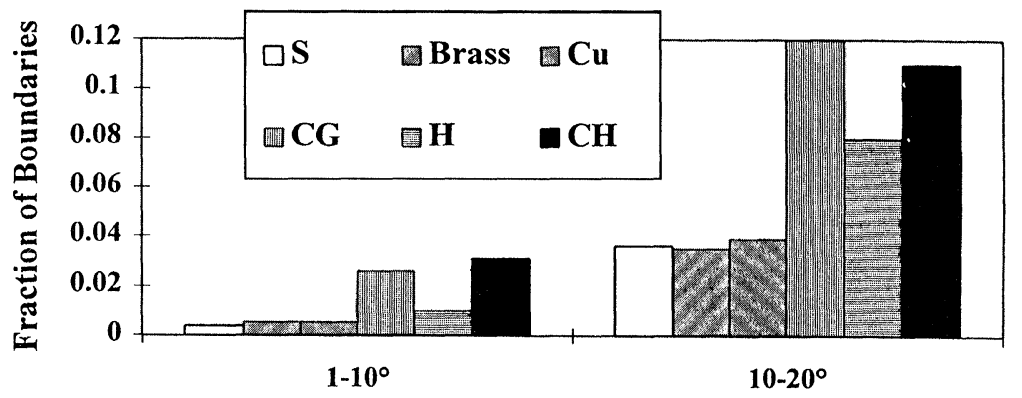

Misorientation Angle

FIGURE 5(a) Fraction of boundaries within $1-10^{\circ}$ and $10-20^{\circ}$ with exact $\mathrm{S}$, Brass, $\mathrm{Cu}, \mathrm{CG}, \mathrm{H}$ and $\mathrm{CH}$ orientations, as observed in $500^{\circ} \mathrm{C} / 3 \mathrm{~s}$ annealed material. 
showed values of boundary fractions similar to $\mathrm{CG} / \mathrm{H} / \mathrm{CH}$. It should be noted that qualitatively similar trends of $1-10^{\circ}$ and $10-20^{\circ}$ boundary distributions were observed at other annealing temperatures and times as well. In other words, irrespective of the annealing conditions, $\mathrm{S} / \mathrm{Brass} / \mathrm{Cu} / \mathrm{Goss}$ grains had the lowest probablities of encountering low angle boundaries. A growing grain can be stopped by particle pinning and/or by grains of similar orientation. Prolonged heating at $500^{\circ} \mathrm{C} / 530^{\circ} \mathrm{C}$ may remove effects of particle pinning. But even in the absence of particle pinning, grains may be 'effectively' pinned and grain growth may be inhibited by low angle/low mobility boundaries. Lower probabilities for $\mathrm{S} / \mathrm{Brass} / \mathrm{Cu} / \mathrm{Goss}$ grains to encounter low angle (and hence low mobility) boundaries might have played a role in their selection for abnormal grain growth.

Another role for GBCD may exist in the possible differences in the low energy, but high mobility, boundaries (e.g. low CSLs). Figure 5(b) plots the total number fraction of CSL boundaries $(\Sigma 3-\Sigma 29)$ with ideal $\mathrm{S}$, Brass, $\mathrm{Cu}$, Goss, $\mathrm{H}$ and $\mathrm{CH}$ orientations in $500^{\circ} \mathrm{C} / 3 \mathrm{~s}$ annealed sample. Fraction of CSL boundaries present among the matrix grains (i.e. among immediate neighbors) are also marked in the figure. As shown in the figure, the $\mathrm{Cu} / \mathrm{S} / \mathrm{Brass} / \mathrm{Goss}$ had slightly higher probabilities of encountering/possessing CSL boundaries (mainly in terms of the low CSL boundaries of $\Sigma 5$ and $\Sigma 9$ ). Measurements at other annealing conditions also showed slight but consistently higher probabilities for ideal $\mathrm{Cu} / \mathrm{S} /$ Brass/Goss orientations to possess low CSL $(\Sigma 3-\Sigma 9)$ boundaries. Orientations with higher probabilities of possessing CSL boundaries may also be favored for abnormal grain growth (Rollett and Mullins, 1997).

Table II shows the average grain sizes for different orientations in $500^{\circ} \mathrm{C} / 3 \mathrm{~s}$ and $3600 \mathrm{~s}$ annealed samples and Figs. 6(a) and (b) plot the observed grain size distributions. Values for average grains (i.e. irrespective of orientations) are also shown. In the initial microstructure (i.e. $500^{\circ} \mathrm{C} / 3 \mathrm{~s}$ ), typically a bimodal grain size distribution was observed. The relatively large fractions of small grains (responsible for such a bimodal size distribution) were possibly due to PSN, as discussed elsewhere (Samajdar et al., 1997). Grain sizes of $\mathrm{Cu}$ and Goss were comparable with average grain sizes, while grains of $\mathrm{S}$ and Brass were slightly larger. At 3600 s (i.e. just before the initiation of abnormal grain growth), the number fraction of small grains decreased and grain 


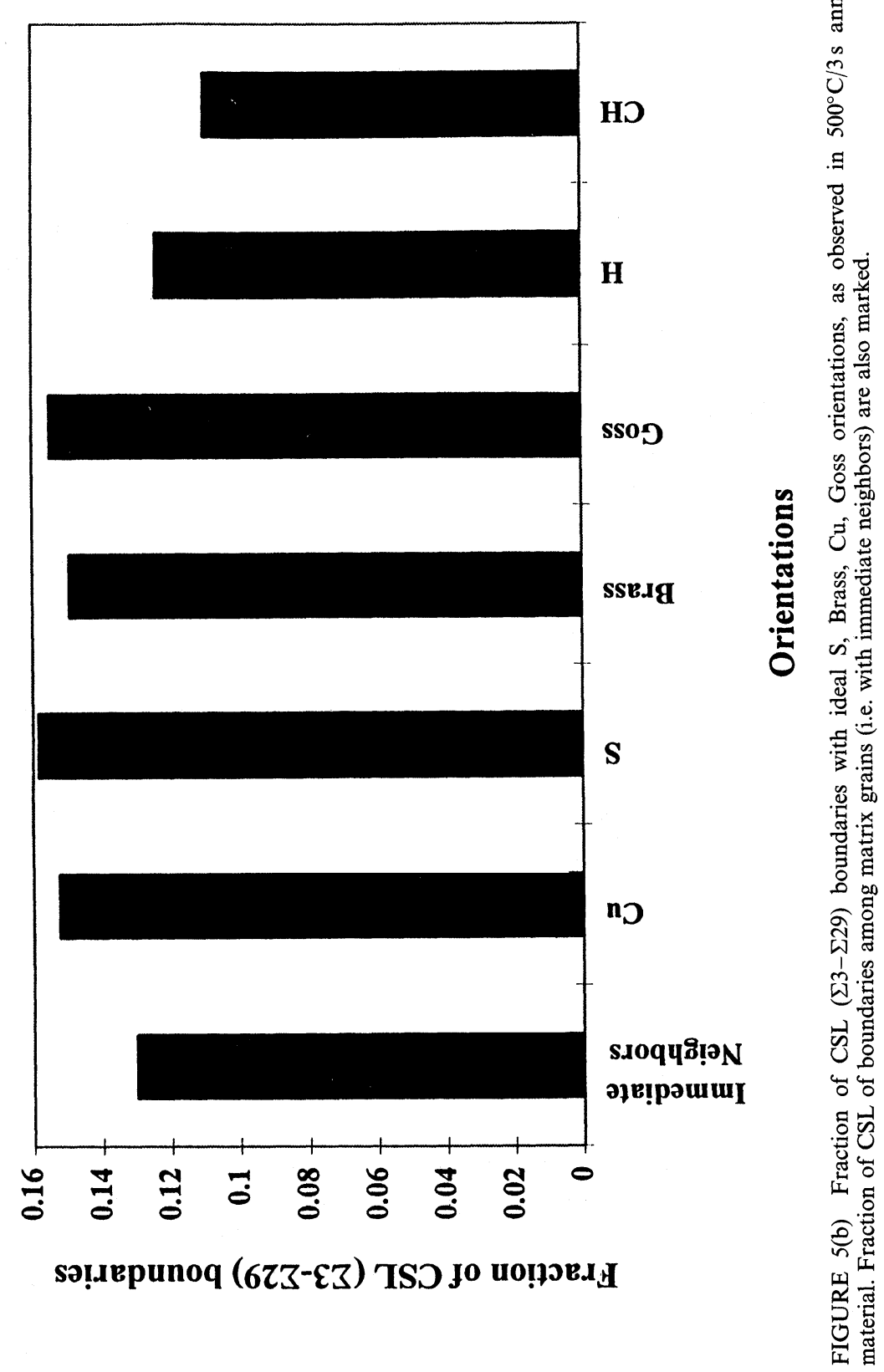


TABLE II Average grain size after annealing at $500^{\circ} \mathrm{C}$ for respectively 3 and $3600 \mathrm{~s}$. Second column refers to all grains (irrespective of orientation) and the next columns refer to grains of specific orientations

\begin{tabular}{lccccc}
\hline Sample & Average $(\mu \mathrm{m})$ & $C u(\mu \mathrm{m})$ & Goss $(\mu \mathrm{m})$ & Brass $(\mu \mathrm{m})$ & $S(\mu \mathrm{m})$ \\
\hline $500^{\circ} \mathrm{C}, 3 \mathrm{~s}$ & 4.35 & 4.5 & 4.37 & 4.96 & 5.23 \\
$500^{\circ} \mathrm{C}, 3600 \mathrm{~s}$ & 6.81 & 8.0 & 7.7 & 8.7 & 9.4 \\
\hline
\end{tabular}

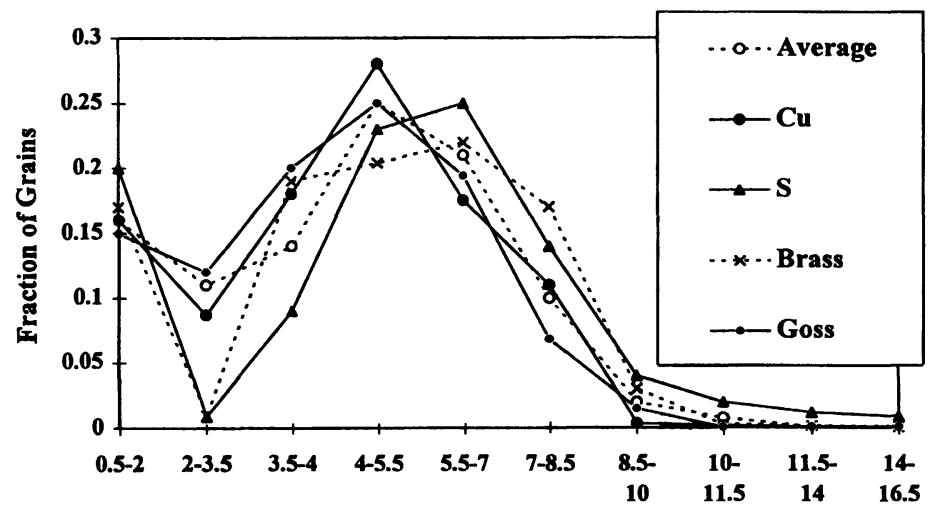

Grain Sizes

FIGURE 6(a) Number fraction of grains of different orientations (within $20^{\circ}$ of the exact orientations) as a function of grain size in $500^{\circ} \mathrm{C} / 3 \mathrm{~s}$ annealed material.

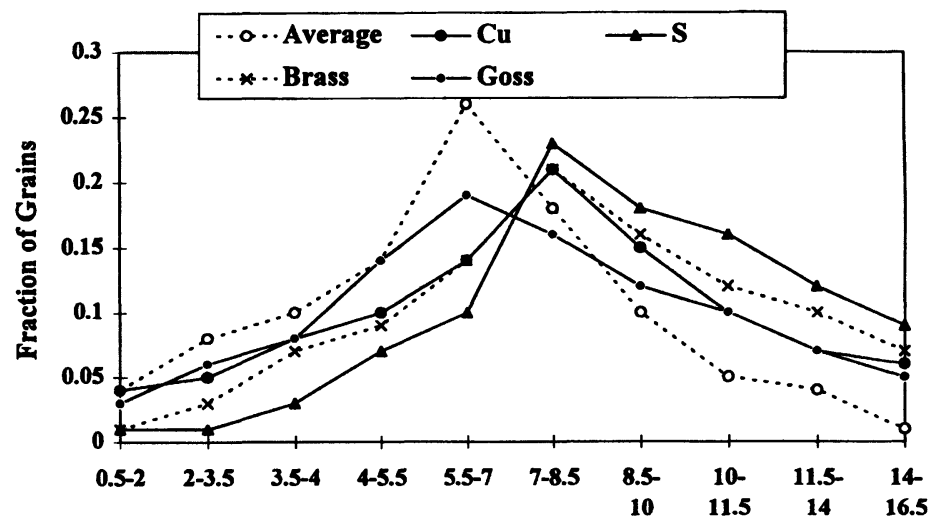

Grain Sizes

FIGURE 6(b) Number fraction of grains of different orientations (within $20^{\circ}$ of the exact orientations) as a function of grain size in $500^{\circ} \mathrm{C} / 3600 \mathrm{~s}$ annealed material. 
size distributions shifted to higher values (see Fig. 6(b)). Interestingly enough, the shift in $\mathrm{S} / \mathrm{Brass} / \mathrm{Cu} / \mathrm{Goss}$ was more than the shift in average grain sizes (which was true even for $\mathrm{Cu}$ and Goss which initially had similar to average grain size distributions, as shown in Fig. 6(a)).

\section{DISCUSSION}

\section{Changes in Grain Size and GBCD with Annealing}

Annealing may change grain sizes. However, in an alloy containing fine dispersoids (like the AA5182 of the present study), the grain size may be restricted by the Zener pinning, as the limiting grain size is expected to be $\left\{(4 r) /\left(3 F_{\mathrm{v}}\right)\right\}$ (where $r$ is the average dispersoid radius and $F_{\mathrm{v}}$ is the volume fraction) (Humphreys and Hatherly, 1995). Our approximate estimation, using backscattered electron imaging in SEM, showed the area fraction of dispersoids as $\mathbf{0 . 0 2}$. Assuming volume fraction and area fraction as similar and considering $r$ as $0.1 \mu \mathrm{m}$, a limiting grain size of $6.7 \mu \mathrm{m}$ is expected (which is close to our observed limiting grain size of 7-8 $\mu \mathrm{m}$ ). After reaching the critical grain size, further grain growth was possible (at $500^{\circ} \mathrm{C} / 530^{\circ} \mathrm{C}$ ) only after dissolution/coarsening of the dispersoids, see Fig. 1.

Annealing and grain growth may change the GBCD, as boundary tensions may reduce the total amount of high energy boundaries (Humphreys and Hatherly, 1995). Computer modelling (Humphreys, 1992) and experimental studies (Randle and Brown, 1989; Watanabe et al., 1989) have shown an increase in low angle and CSL boundaries with annealing. Our results indicate that in the commercial alloy AA5182, the total amount of extremely low angle $\left(1-5^{\circ}\right)$ boundaries increase quite dramatically with annealing. However, boundaries within $5-20^{\circ}$ and also the CSL boundaries $(\Sigma 3-\Sigma 29)$ did not change noticeably with annealing time/temperature, see Figs. 2 and 3. Increase in $1-5^{\circ}$ boundaries was more at $470^{\circ} \mathrm{C}$, when dispersoids were stable and grain boundaries were effectively pinned, that at $500^{\circ} \mathrm{C} / 530^{\circ} \mathrm{C}$, when limited grain growth was observed. If (i) boundary tension is primarily responsible for changes in GBCD (in our case increase in $1-5^{\circ}$ boundaries) and (ii) pinned boundaries are more affected by boundary tension, then a combination of (i) and (ii) may explain our results. One may make such easy speculations and explain observed 
trends in experimental results, but much remains to be learnt on the interaction of grain boundaries and dispersoids - especially when it may involve dissolution/coarsening.

\section{Abnormal Grain Growth}

Abnormal grain growth was observed after dispersoid dissolution/ coarsening, as mainly $\mathrm{S}$ (and also some Brass and $\mathrm{Cu}$ ) grains grew abnormally. Even in the starting as recrystallized microstructure $\left(500^{\circ} \mathrm{C} / 3 \mathrm{~s}\right.$ annealed), the $\mathrm{S}$ and Brass grains were slightly larger than the average (see Table II). With further annealing, the size advantage increased. Grain size distributions for $\mathrm{Cu} / \mathrm{Goss}$ were similar to that of average grains (see Table II and Fig. 6(a)). However, with subsequent annealing $\mathrm{Cu} / \mathrm{Goss}$ grains gained a limited size advantage (as in Table II and Fig. 6(b)). Only a statistical approach to the grain size distributions (Abbruzzese and Lücke, 1986) may not be sufficient to explain such changes. Our observations on GBCD may indicate another possibility.

Considering the growth of an isolated grain, simple 2-dimensional modelling (Rollett and Mullins, 1997) has shown that high mobility and low boundary energy may promote abnormal grain growth. $\mathrm{S} / \mathrm{Brass} / \mathrm{Cu} / \mathrm{Goss}$ grains had the lowest probability of encountering low angle/low mobility boundaries, but higher probability of possessing low energy/CSL boundaries, see Fig. 5. Such a combination may favor abnormal grain growth (Rollett and Mullins, 1997). It should be noted that the values reported in Fig. 5 are the average of the calculated values for all variants of ideal $\mathrm{S} / \mathrm{Brass} / \mathrm{Cu} / \mathrm{Goss}$ orientations. $\mathrm{S}$ has four variants, while Brass/Cu/Goss have two each. Thus for a particular variant, especially for $S$, the probabilities of encountering low mobility or high energy boundaries may be lower or higher than the reported values of Fig. 5. Such lower/higher probabilities were observed locally for some, but not all, of the largest $\mathbf{S}$ grains. During abnormal grain growth, the final microstructure and texture is basically due to a few overgrown grains. Larger than average grain sizes for S (see Fig. 6) and also the fact that some of such large $S$ grains may be favorably oriented/placed to encounter more of high mobility and low energy boundaries, possibly determined the orientation selection for abnormal grain growth in this material. 
Grain boundary pinning by randomly distributed fine dispersoids may be obtained from Zener pinning pressure as $\left\{\left(3 F_{\mathrm{v}} \gamma\right) /(2 r)\right\}$, where $F_{\mathrm{v}}$ and $r$ are the volume fraction and average radius of the dispersoids and $\gamma$ is the specific energy of the boundary with the dispersoids (Humphreys and Hatherly, 1995). For a low energy boundary (e.g. low CSL boundaries) $\gamma$ and correspondingly the Zener pinning pressure is expected to be lower. In other words, a low CSL boundary may be less susceptible to dispersoid pinning. This may also explain the observation that growth of orientations (i.e. S/Brass/Cu/Goss), with slightly higher probability for encountering/possessing CSL boundaries, were somewhat favored (especially for $\mathrm{Cu} / \mathrm{Goss}$ - which did not possess an initial size advantage (see Fig. 6 and Table II)). Experimental observations in $\mathrm{Si}-\mathrm{Fe}$ (Harase and Shimuzu, 1988) had also shown that Goss grains may not possess a size advantage in the initial microstructure, but still may get selected for abnormal grain growth. Such a phenomenon was explained from the GBCD relationship between Goss and matrix and specific grain boundary migration characteristics associated with the particle pinning (Harase and Shimuzu, 1988). Our observations on the favored growth of $\mathrm{S} / \mathrm{Brass} / \mathrm{Cu} / \mathrm{Goss}$ may follow the same logic.

\section{CONCLUSIONS}

(1) Limited grain growth to a critical grain size was observed immediately after primary recrystallization. Further grain growth was only possible after prolonged annealing at $500^{\circ} \mathrm{C} / 530^{\circ} \mathrm{C}$, which dissolved/coarsened the dispersoids responsible for grain boundary pinning.

(2) Prolonged annealing (from 30 to $21600 \mathrm{~s}$ ) was observed to increase the fraction of $1-5^{\circ}$ boundaries. The increase was more at $470^{\circ}$ (when grain growth was effectively arrested) than at $500^{\circ} \mathrm{C} / 530^{\circ} \mathrm{C}$ (when limited grain growth was observed). However, the nature of the $5-20^{\circ}$ and CSL boundaries did not change significantly with annealing.

(3) Abnormal grain growth was observed after $500^{\circ} \mathrm{C} / 36000 \mathrm{~s}$ and $530^{\circ} \mathrm{C} / 21600 \mathrm{~s}$ annealing, as mainly $\mathrm{S}$ (and also some brass and $\mathrm{Cu}$ ) grains grew abnormally. 
(4) In the starting as recrystallized microstructure, Brass and S grains had a slight size advantage. The size advantage improved with subsequent annealing. Interestingly enough, $\mathrm{Cu}$ and Goss grains (which did not have a size advantage in the starting as recrystallized microstructure) also gained limited size advantage during annealing.

(5) $\mathrm{S} / \mathrm{Brass} / \mathrm{Cu} / \mathrm{Goss}$ grains had lower probabilities of encountering low angle boundaries, but higher probabilities for encountering/ possessing CSL boundaries. These might have played a role in improving the size advantage for $\mathrm{S} /$ Brass, and for acquiring limited size advantage for $\mathrm{Cu} / \mathrm{Goss}$.

(6) Both the size advantage and GBCD possibly determined the selection mechanism for abnormal grain growth.

\section{Acknowledgements}

Financial support from FKFO grant no: G.0252.96 and supply of the rolled material from Hoogovens Aluminium are well appreciated. Part of the research was carried out in the frame of an European COST 512 action.

\section{References}

Abbruzzese, G. and Lücke, K. (1986). Acta Metall., 34(5), 905-914.

Brandon, D.G. (1966). Acta Metall., 14, 1479-1485.

Bunge, H.J. (1982). Texture Analysis in Materials Science, London: Butterworths.

Chiba, A., Handa, S., Watanabe, T., Abe, T. and Obana, T. (1994). Acta Metall. Mater., 42(5), 1733-1738.

Harase, J. and Shimuzu, R. (1988). Trans. JIM, 29(5), 388-398.

Hayakawa, Y. and Szpunar, J.A. (1997). Acta Mater., 45(3), 1285-1295.

Humphreys, F.J. (1992). Scripta Metall., 27, 1557-1562.

Humphreys, F.J. and Hatherly, M. (1995). Recrystallization and Related Annealing Phenomena, UK: Elsevier Sci. Ltd.

Palumbo, G., King, P.J., Aust, K.T., Erb, U. and Lichtenberger, P.C. (1991). Scripta Metall. Mater., 25, 1775-1780.

Rabet, L. (1996). Ph.D. Thesis (in Dutch), ISBN No: 90-5682-021-4, Katholieke Universiteit Leuven, Belgium.

Randle, V. and Brown, A. (1989). Phil. Mag. A, 59(5), 1075-1089.

Randle, V. (1992). Microtexture Determination and its Application, London: The Inst. of Mater.

Ratchev, P., Verlinden, B. and Van Houtte, P. (1995). Acta Metall. Mater., 43(2), 621-629.

Rollett, A.D. and Mullins, W.W. (1997). Scripta Mater., 36(9), 975-980.

Samajdar, I. and Doherty, R.D. (1994). Scripta Metall. Mater., 31(5), 527-530.

Samajdar, I., Rabet, L., Verlinden, B. and Van Houtte, P. (1997). Submitted to the special issue on recrystallization in ISIJ (1998). 
Smith, D.A. and Pond, R.C. (1976). Int. Metals Rev., 21, 61-74.

Van Houtte, P. (1995). MTM-FHM software and Manual, Version 2, ed. MTMKULeuven, Belgium.

Watanabe, T., Fujii, H., Oikawa, H. and Arai, K.I. (1989). Acta Metall., 37, 941-952.

Watanabe, T. (1992). Scripta Metall. Mater., 27, 1497-1502. 